\title{
Barajın Kısmi ve Ani Yıkılması Durumlarında Oluşan Taşkın Dalgalarının Çarpıtılmış Fiziksel Model ile Deneysel Olarak Araştırılması
}

\section{Experimental Investigation of The Flood Wave Propagation Due to Partial and Sudden Dam Break by Distorted Physical Model}

\author{
Tanıl Arkış ${ }^{*}$, , Mehmet Şükrü Güney² \\ ${ }^{1}$ Dokuz Eylül Üniversitesi Fen Bilimleri Enstitüsü, Hidrolik-Hidroloji ve Su Kaynakları Programı, İzmir, TÜRKIYE \\ 2 İzmir Ekonomi Üniversitesi Mühendislik Fakültesi, İnşaat Mühendisliği Bölümü, İzmir, TÜRKIYE \\ Sorumlu Yazar / Corresponding Author*: tanilarkis@gmail.com \\ Geliş Tarihi / Received: 25.02.2020 \\ Araștırma Makalesi/Research Article \\ Kabul Tarihi / Accepted:28.04.2020 \\ DOI:10.21205/deufmd.2020226622
}

Atıf șekli/How to cite: ARKIS, T., GUNEY, M.S., (2020). Barajın Kısmi ve Ani Ylkılması Durumlarında Oluşan Taşkın Dalgalarının Çarpıtılmış Fiziksel Model ile Deneysel Olarak Araștırılması. DEUFMD 22(66), 887-896.

Öz

Barajlar su temini, sulama, enerji üretimi ve taşkın kontrolü gibi faydalı işlevleri olan önemli su yapılarıdır. Çok büyük can ve mal kaybına sebep olan baraj yıkılması deneysel ve sayısal olarak uzun yıllardan beri araştırılmaktadır. Barajın yıkılması durumunda oluşan taşkın dalgalarının yayılması Dokuz Eylül Üniversitesi Hidrolik Laboratuvarı açık alanında inşa edilmiş olan Ürkmez Barajı ve mansap bölgesinin çarpıtılmış fiziksel modeli yardımıyla deneysel olarak araştırılmıştır. Model ilk yazarın burslu doktora öğrencisi olarak görev aldığı TÜBİTAK 110M240 nolu proje kapsamında tasarlanmış ve inşa edilmiştir. Yatay ölçeği 1/150 ve düşey ölçeği 1/30 olan bu fiziksel model baraj gölünü ve baraj mansabında denize kadar olan yerleşim yerini de içermektedir. Modelin geometrik parametreleri mevcut haritalar ve benzeşim kanunları kullanılarak belirlenmiştir. Bu bağlamda 300 $\mathrm{m}^{2}$ lik alanda inşa edilmiş olan modelde baraj gölü yaklașık olarak $11 \mathrm{~m}^{3}$, baraj uzunluğu 2,84 m ve yüksekliği 1,07 m'dir. Ürkmez Barajı fiziksel model için makul boyutlara sahip olduğu ve yerleşim yerine yakın olduğu için seçilmiştir. Evler ve karayolu gibi hususlar da modelde yerleştirilmiştir. Su derinlikleri e+ WATER L seviye ölçerleri kullanılarak ölçülmüştür. Hızlar Ultrasonic Velocity Profiler (UVP) algılayıcıları ile belirlenmiştir. Taşkın dalgasının yayılması kamera vasıtasıyla kaydedilmiştir. Elde edilen deneysel bulgular değerlendirilmekte ve bunların prototipte karşılık gelen değerleri yorumlanmaktadır.

Anahtar Kelimeler: Fiziksel model, çarpıtılmış model, benzeșim kanunları, baraj yıkılması, taşkın yayılması. 


\begin{abstract}
Dams are important water structures which serve to several beneficial purposes such as water supply, irrigation, energy production and flood control. Dam break causes important losses of life and property; hence it was investigated for several years. Flood propagation due to partial and sudden dam break was studied experimentally by means of a distorted physical model of Ürkmez Dam and its downstream region, built in the open area of Hydraulics Laboratory of Dokuz Eylül University. The physical model was designed and built in the scope of the project TÜBİTAK $110 \mathrm{M} 240$ at which the first author performed his Ph. D. studies. The horizontal and vertical scales of the physical model are $1 / 150$ and $1 / 30$, respectively. It contains the reservoir, the dam and the downstream part of the dam until the sea. The geometric parameters of the model were determined by using the similitude laws and the available maps. Accordingly, in the model located in an area of $300 \mathrm{~m}^{2}$, the reservoir is approximately $11 \mathrm{~m}^{3}$, the dam has a length of $2.84 \mathrm{~m}$ and a height of $1.07 \mathrm{~m}$. Ürkmez dam was chosen since it has reasonable dimensions and it's located close to Ürkmez village. The features such as the residences and highway were also located in the physical model. The water depths were measured by using the level sensors e+ WATER L. The velocities were determined by Ultrasonic Velocity Profiler (UVP) transducers. The flood wave propagation was recorded by means of a camera. The obtained experimental findings are evaluated and their corresponding prototype values are interpreted.

Keywords: Physical model, distorted model, similarity laws, dam break, flood propagation.
\end{abstract}

\section{Giriş}

Barajlar içme ve kullanma suyu temini, enerji üretimi, sulama, tașkın önleme, rekreasyon, balıkçılık ve bunun gibi birçok faydalı işlevleri olan su yapılarıdır. Barajlar dolu savak yetersizliği, yapısal hatalar (temel problemleri), şev kaymaları, heyelanlar, sızma ve borulanma, suyun baraj gövdesi üstünden așması, deprem gibi farklı nedenlerle yıkılabilmektedir. Baraj yıkılması durumunda büyük felaketler yaşanmakta, çok öneli can ve mal kayıpları oluşmaktadır. $\mathrm{Bu}$ nedenlerle baraj yıkılması durumunda olușan tașkın dalgalarının yayılması konusunda geçmişte birçok deneysel ve sayısal araştırma gerçekleştirilmiş ve gerçekleştirilmeye devam edilmektedir. Mevcut deneysel çalışmaların çok büyük çoğunluğunda baraj yıkılması senaryoları kanala yerleștirilen bir kapağın kaldırılması ile gerçekleştirilmiştir. Baraj gövdesi inşa edilerek yapılan deneysel çalışmalar son derece azdır. Bu alanda yapılmış bazı önemli çalışma aşağıda verilmektedir.

Leal vd, [1] deneylerini 19,2 m uzunluğunda, $0,50 \mathrm{~m}$ genişliğinde ve $0,70 \mathrm{~m}$ yüksekliğinde haraketli tabana sahip dikdörtgen bir kanalda yapmışlardır. Haznenin mansap kısmındaki kanalda yıkılmadan önce belli bir derinlikte su ile çalışmışlardır. Yıkılmayı hareketli kapak ile sağlamışlardır.
Bellos [2] iki boyutlu dalga yayılmasını ıslak ve kuru yatak koşullarında deneysel olarak araştırmıştır. Derinlik değişimlerini ve dalga yayılma davranıșını analiz etmek için basınç algılayıcıları kullanmıștır. Deneysel bulgular önceden geliștirilmiș kararsız iki boyutlu akım programı ile elde edilen sonuçlar ile karşılaştırılmıştır.

Testa vd. [3] Toce River vadisinin kentsel bölümüne karşıllk gelen $50 \mathrm{~m}$ uzunluklu ve 1:100 ölçekli modeli üzerinde tașkın dalgasının yayılmasını incelemişlerdir. Binalar $15 \mathrm{~cm}$ kenar uzunluklu küp șeklindeki beton bloklarla temsil edilmişlerdir.

Alcrudo ve Mulet] [4] yıkılan Tous Barajı'nın mansabında $5 \mathrm{~km}$ mesafede yer alan kasabanın taşkın dalgalarından etkilenmesini matematiksel olarak modellemişlerdir. Böylece, Tous Barajı'ndaki verilerden yola çıkarak elde ettikleri matematiksel modelleri diğer gerçek değerler ile karşılaştırmışlardır.

Bu çalışmada yapıldığı gibi hem baraj gölünü ve gövdesini hem de barajın mansap bölgesini içeren ölçekli bir fiziksel model üzerinde yapılan deneysel çalışmalar literatürde mevcut değildir. Ürkmez barajının fiziksel modelinin tasarlanıp inşa edilerek baraj yıkılması nedeniyle oluşan taşkın dalgası yayılmasının üç boyutlu olarak incelenmesi bu çalışmanın özgün değerini oluşturmaktadır. 


\section{2. Çarpıtılmış Fiziksel Model}

İncelenen alanın genel görünüşü Şekil 1'de verilmektedir [5]. Bu fiziksel model TÜBITTAK 110M240 nolu proje kapsamında tasarlanmış ve inşa edilmiştir. Bu proje kapsamında hem trapez veya üçgen şeklindeki gedikler nedeniyle oluşan kısmi yıkılma hem de ani yıkılma deneyleri gerçekleştirilmiştir.

Fiziksel model yerçekimi kuvveti daha etkin olduğundan Froude benzeșim kanununa göre tasarlanmıștır. Yatay ve düșey ölçekler modelin belirlenen alana uygun olarak inşa edilerek çalıştırılabileceği ve hızların ve derinliklerin yeterli hassasiyetle ölçülebileceği şekilde seçilmiştir. Yatay ölçeğin 1/150 ve düşey ölçeğin 1/30 olarak seçilmesiyle aşağıdaki ölçekler tanımlanabilmektedir:

Çarpıklık katsayısı:

$n=\frac{\ell_{z r}}{\ell_{x r}}=5$

Eğim ölçeği:

$S_{r}=\ell_{z r} / \ell_{x r}=5$

Enkesit alanı ölçeği:

$A_{r}=\ell_{x r} \ell_{z r}=1 / 4.500$

Hacim ölçeği:

$V_{r}=l_{x r}^{2} \ell_{z r}=1 / 675.000$

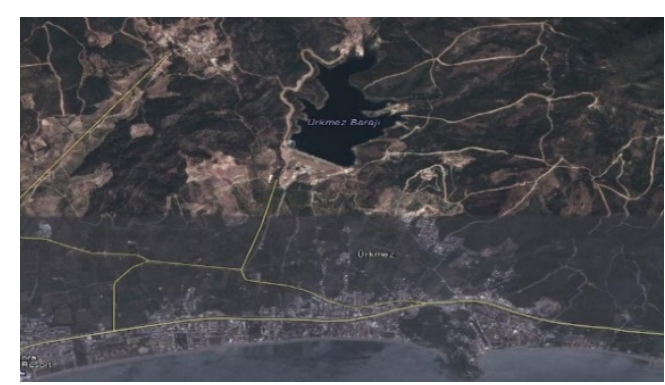

Şekil 1. İncelenen alanın genel görünüşü

Doğadaki Ürkmez Barajı (prototip) ve inşa edilen fiziksel modelinin geometrik özellikleri Tablo 1'de verilmektedir:
Tablo 1. Ürkmez Barajı ve modelinin geometrik özellikleri

\begin{tabular}{|c|c|c|}
\hline Özellik & Prototip & $\begin{array}{c}\text { Fiziksel } \\
\text { model }\end{array}$ \\
\hline Kret uzunluğu (m) & 426 & 2,84 \\
\hline Kret genişliği (m) & 12 & 0,08 \\
\hline $\begin{array}{l}\text { Barajın temelden } \\
\text { yüksekliği (m) }\end{array}$ & 32 & 1,07 \\
\hline $\begin{array}{c}\text { Baraj gölü minimum } \\
\text { hacmi }\left(\mathrm{m}^{3}\right)\end{array}$ & 375.000 & 0,556 \\
\hline Baraj gölü & & \\
\hline$\underset{\left(\mathrm{m}^{3}\right)}{\operatorname{maksimum}}$ hacmi & 8.625 .000 & 12,778 \\
\hline $\begin{array}{l}\text { Baraj gölü normal } \\
\text { seviye hacmi }\left(\mathrm{m}^{3}\right)\end{array}$ & 7.950 .000 & 11,778 \\
\hline $\begin{array}{l}\text { Baraj gölü aktif } \\
\text { hacmi }\left(\mathrm{m}^{3}\right)\end{array}$ & 7.575 .000 & 11,222 \\
\hline
\end{tabular}

Hız ve zaman ölçekleri için aşağıdaki ifadeler yazılabilmektedir [6].

Froude hız ölçeği:

$v_{r}=v_{x r}=\sqrt{\ell_{z r}}=1 / 5,48$

Zaman ölçeği:

$t_{r}=\frac{l_{x r}}{\sqrt{l_{z r}}}=\frac{1}{n} \sqrt{\ell_{z r}}=1 / 27,4$

\section{3. Çarpıtılmış Fiziksel Modelin İnşaatı}

Fiziksel model için ayrılmış bulunan yaklaşık $300 \mathrm{~m}^{2}$ 'lik alanın inşaat öncesi görüntüsü Şekil 2'de verilmektedir.

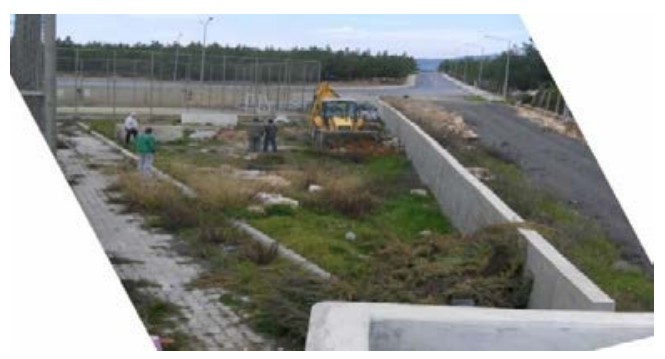

Şekil 2. Model inşaatı öncesinde tahsis edilen alanın görünüşü

İlgili haritalardan elde edilen enkesitlerin modeldeki boyutları belirlendikten sonra; bu enkesitler metal levhalar kullanılarak imal 
DEÜ FMD 22(66), 887-896, 2020

edilmiş ve metal profillere kaynak yapılarak yerleştirilmişlerdir (Şekil 3).

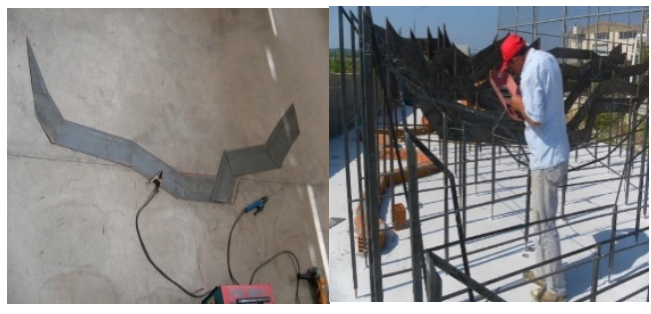

Şekil 3. Enkesitlerin imal edilmesi ve yerleştirilmesi

Göl bölgesi etrafı duvarla örüldükten sonra, Șekil 4'te gösterildiği gibi içi dolgu malzemesi ile doldurulmuştur.

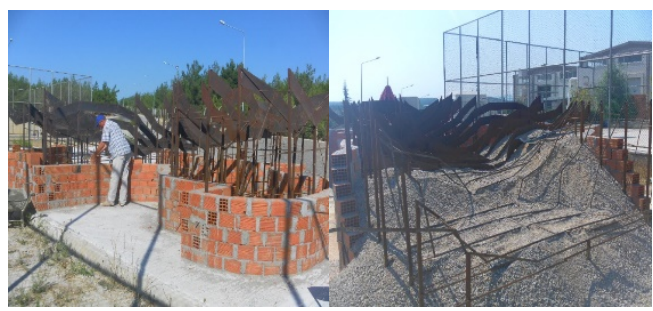

Şekil 4. Göl bölgesinin duvarla örülmesi ve dolgu malzemesi ile doldurulması

Mansap bölgesi de benzer bir şekilde inşa edilmiştir (Şekil 5).

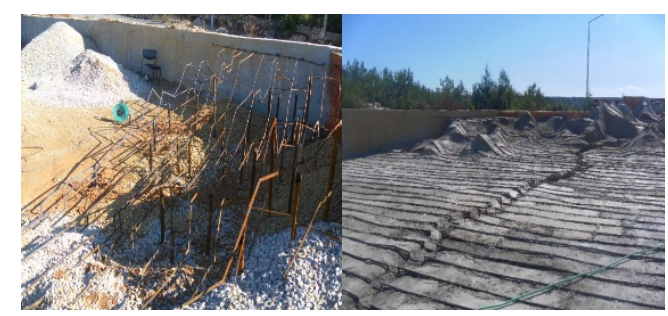

Şekil 5. Mansap bölgesinde kesitlerin yerleștirilmesi ve dolgu malzemesiyle doldurulması

Kısmi yıkılmayı temsil etmek üzere trapez prizma ve üçgen prizma șeklinde hareketli kısımlar içeren baraj gövdeleri metal malzemeden imal edilmiştir, Şekil 6'da trapez şeklinde gedik açılması ve üçgen şeklinde gedik açılması senaryolarında kullanılan baraj gövdeleri verilmektedir.

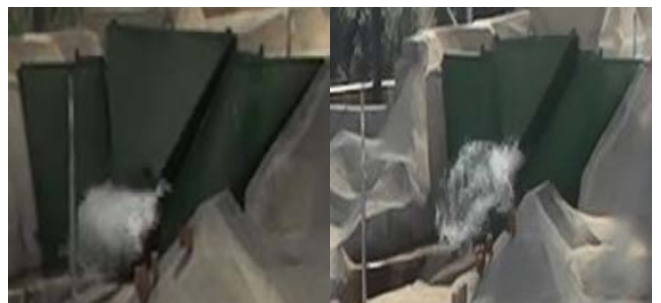

Şekil 6. Hareketli trapez prizma ve hareketli üçgen prizma içeren baraj gövdeleri

Ani yıkılma, Şekil 7'de gösterilen dikdörtgen şeklindeki metal kapağın aniden devrilmesi ile gerçekleștirilmiștir.

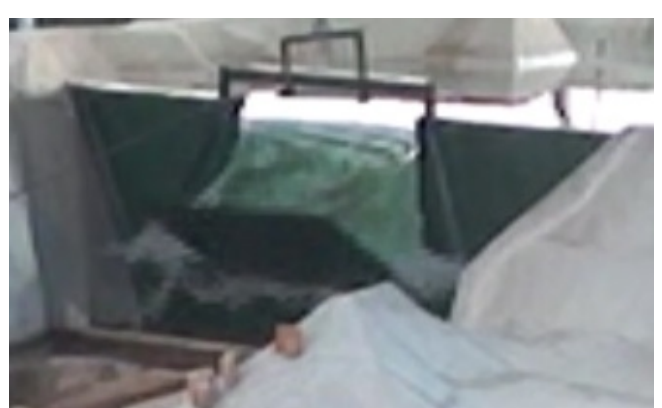

Şekil 7. Ani yıkılmanın olușturulmasında kullanılan kapak

Su derinlikleri Şekil 8'de gösterilen e+ WATER L seviye ölçerleri kullanılarak ölçülmüştür.

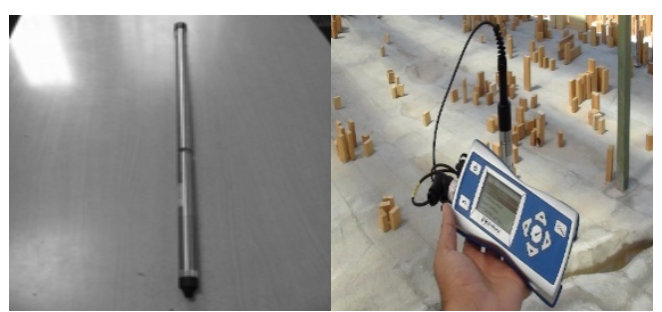

Şekil 8. Su derinliklerinin ölçülmesinde kullanılan seviye ölçerler

Hızlar Ultrasonic Velocity Profiler (UVP) algılayıcıları ile belirlenmiştir. Ölçüm düzeneği Şekil 9'da verilmektedir [7]. 
DEÜ FMD 22(66), 887-896, 2020

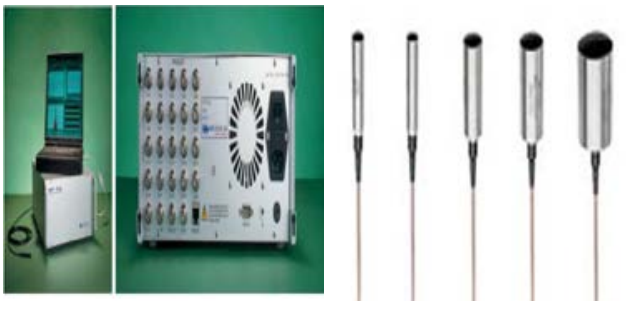

Şekil 9. Hızların ölçülmesinde kullanılan UVP cihazı ve algılayıcıları

Yerleşim yerindeki bina yükseklikleri göz önüne alınarak binalar ve Seferihisar-Kuşadası karayolu yerleștirilmiştir. Tamamlanmış modelin genel bir görünüşü Şekil 10 'da deney cihazların konumlarını gösteren kroki Şekil11'de verilmektedir.

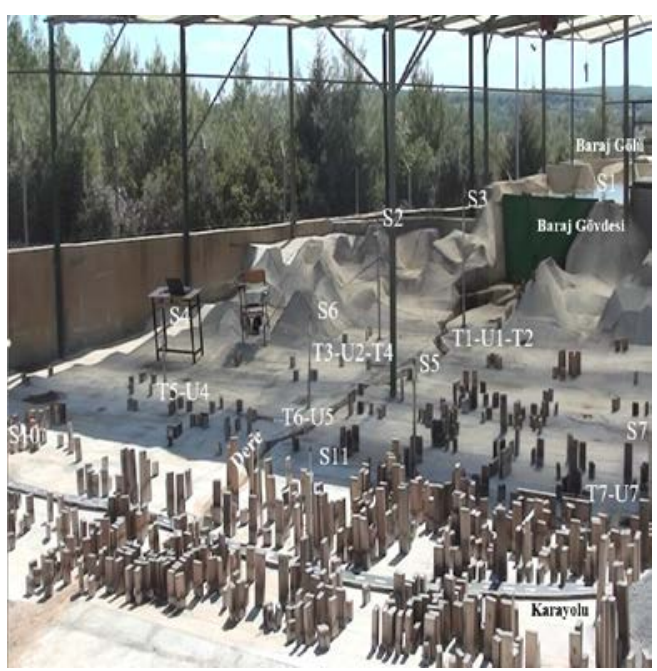

Șekil 10. Fiziksel modelin inșaatı bittiğinde genel görüntüsü ve ölçüm cihazlarının konumları

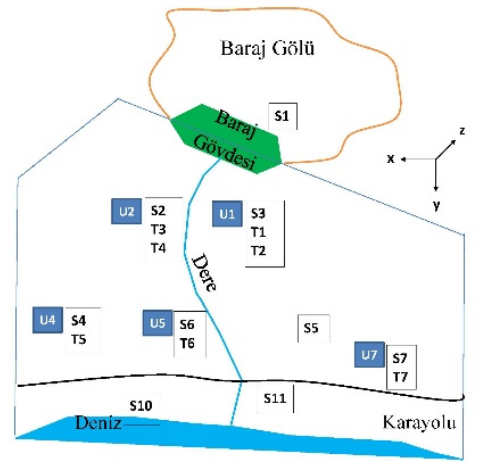

Şekil 11. Ölçüm cihazlarının konumlarını gösteren kroki

\section{Deneysel Bulgular}

TÜBİTAK 110M240 nolu proje kapsamında gerçekleştirilen bu çalışmalarda; gerçek boyutlarıla temsil edilen baraj gövdesinde trapez şeklinde bir gedik açılması durumunda elde edilen deneysel sonuçlar [8] ve [9] yayınlarında yer almaktadır.

Seviye ölçer ve hızölçerlerin konumları Şekil 10 'da gösterilmektedir. S1 seviye ölçeri baraj gölü içine yerleştirilmiş olup bu cihazdan ölçülen değerler ile baraj gölü seviyesindeki değişimler elde edilmiştir. Böylece deneyler öncesinde model için çıkartılmış bulunan ve Şekil 12'de verilen hacim-seviye eğrilerinden yararlanılarak baraj gölündeki hacım azalmaları ve dolayısıyla taşkın hidrografları belirlenmiştir.

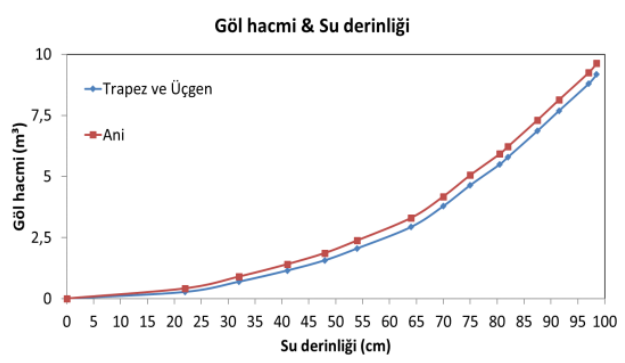

Şekil 12. Trapez - üçgen gedik ve ani yıkılma durumunda hacim-seviye eğrisi

\subsection{Su derinlikleri}

Baraj gölünde $9,95 \mathrm{~m}^{3}$ hacminde su varken elde edilen bulgular örnek olarak verilmektedir.

Şekil 13'te deney esnasında fiziksel modelin gölünde su hacminin zamanla değișimi verilmektedir. Su hacmindeki değişim miktarlarının zaman aralıklarına bölünmesiyle belirlenen giriş hidrografları Şekil 14'te verilmektedir. 


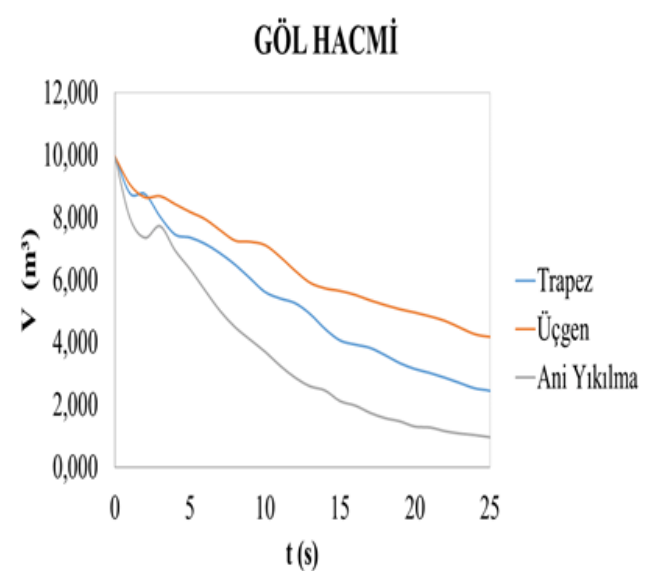

Şekil 13. Göl hacminin zamanla değişimi

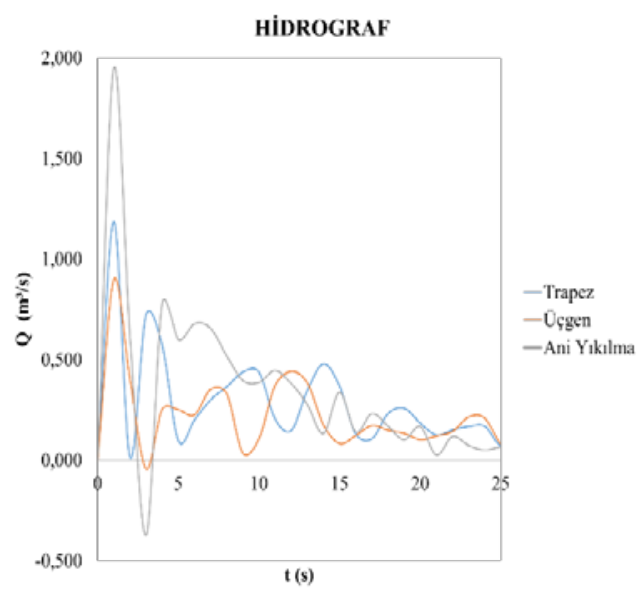

Şekil 14. Oluşturulan hidrograflar

Mansap bölgesinin değișik noktalarında ölçülen su derinlikleri Şekil 15'te verilmektedir. Deneyler tekrarlanarak ölçüm hataları en aza indirilmeye çalışılmıştır. Aşağıda verilen eğriler tekrarlanan iki deneyin ortalama sonuçlarına karşıllk gelmektedir.
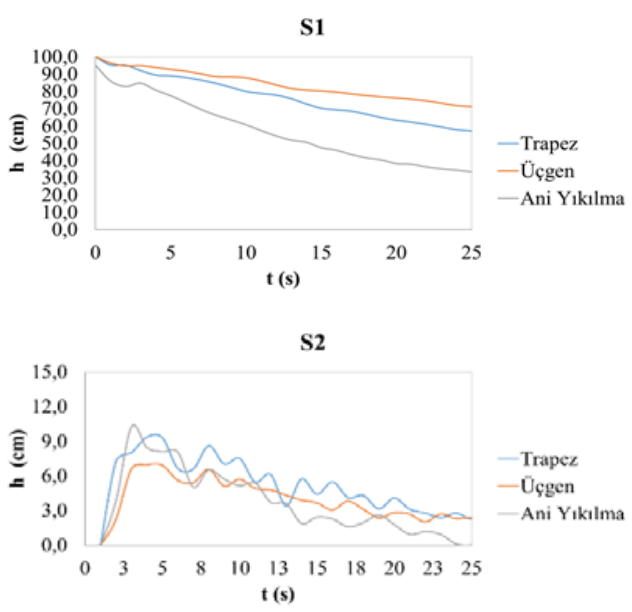

S3

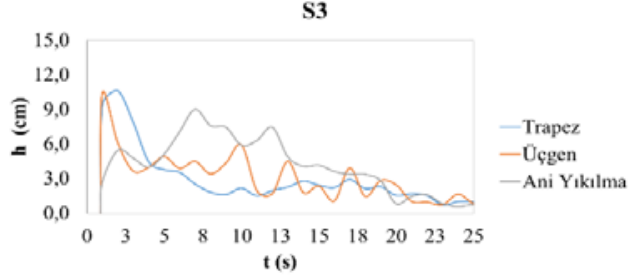

S4

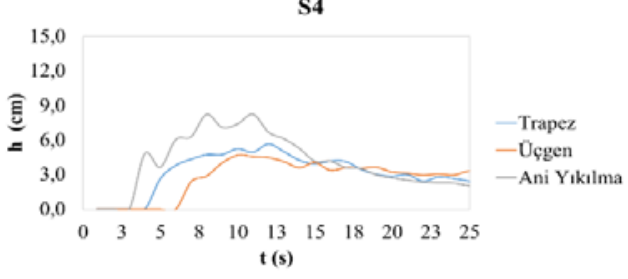

S5

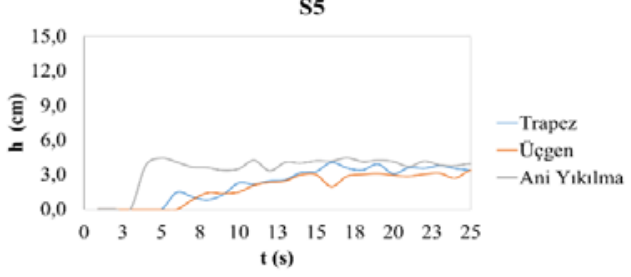

S6

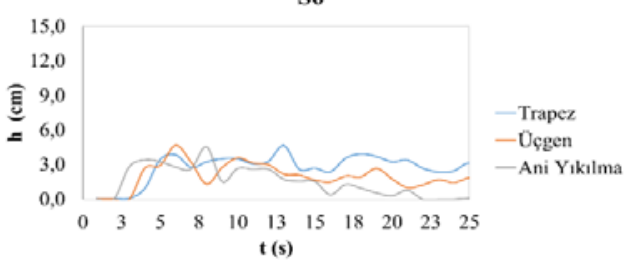

Şekil 15. Seviye çubuklarından ölçülen zamana bağlı su derinlikleri 
S7

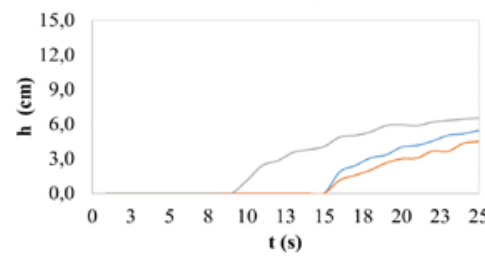

S10

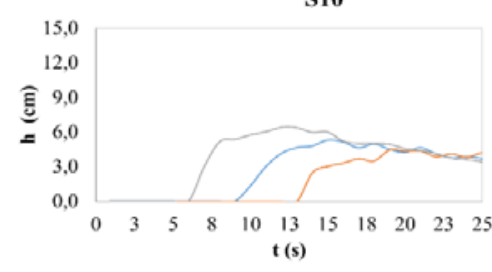

S11

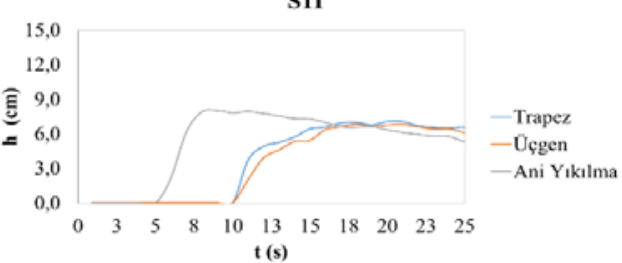

Şekil 15. Seviye çubuklarından ölçülen zamana bağlı su derinlikleri (devam)

\subsection{Hizlar}

Değişik kesitlerde ölçülen ortalama hız değerleri Şekil 16'da verilmektedir.

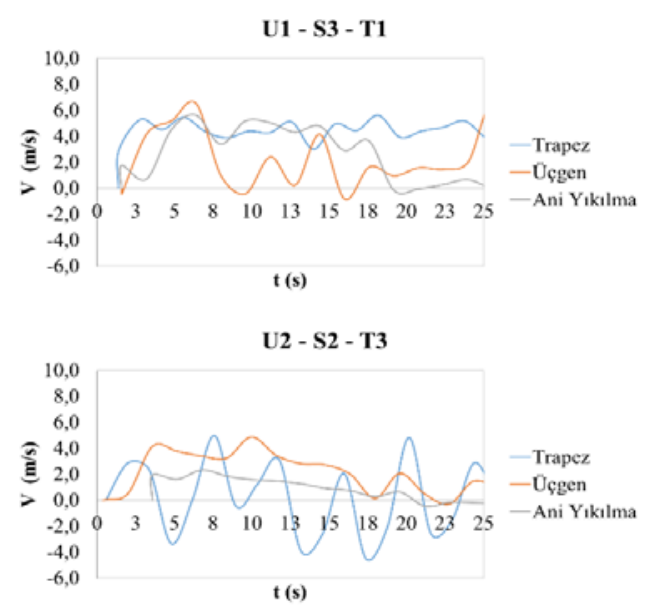

Şekil 16. Hız ölçerlerle elde edilen zamana bağlı hız değerleri

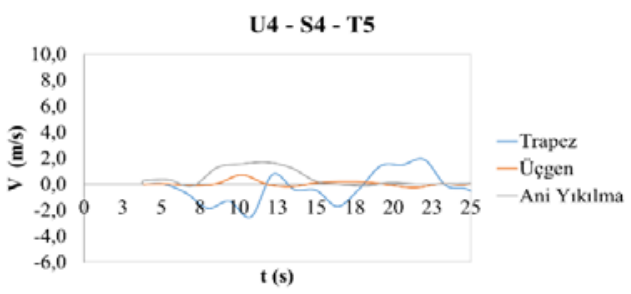

U5 - S5 - T7

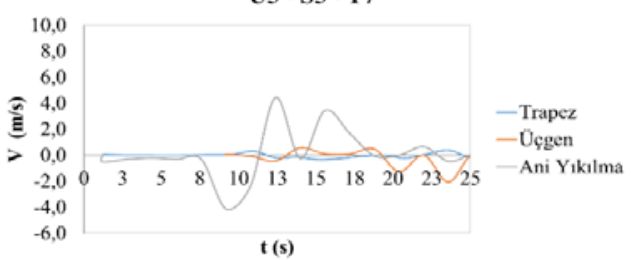

Şekil 16. Hız ölçerlerle elde edilen zamana bağlı hız değerleri (devam)

\subsection{Taşkın dalgalarının yayılması}

Taşkın dalgasının 2 s sonra ulaştığı noktalar trapez gedik, üçgen gedik ve ani yıkılma durumlarında sırasıyla Şekil 17, 18 ve 19'da verilmektedir.

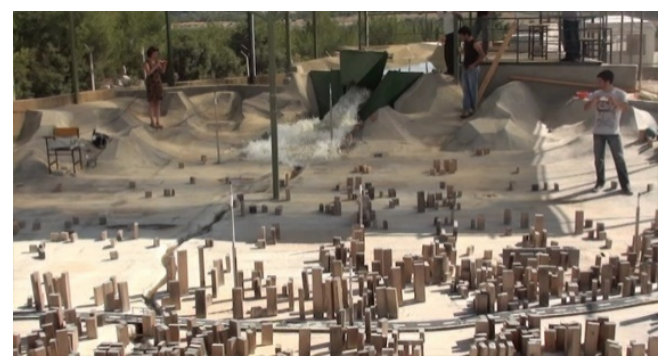

Şekil 17. Trapez gedik durumunda taşkın dalgasının $2 \mathrm{~s}$ sonra ulaştığı noktalar

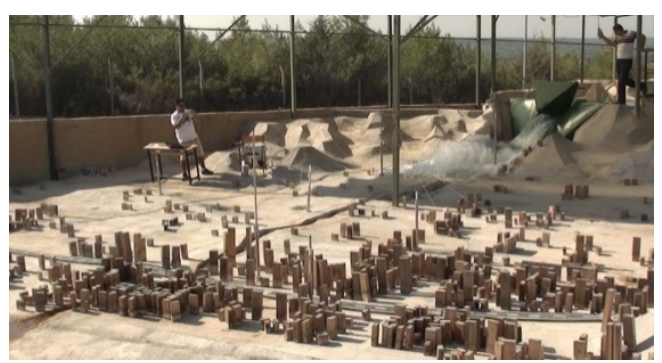

Şekil 18. Üçgen gedik durumunda taşkın dalgasının $2 \mathrm{~s}$ sonra ulaştığı noktalar 
DEÜ FMD 22(66), 887-896, 2020

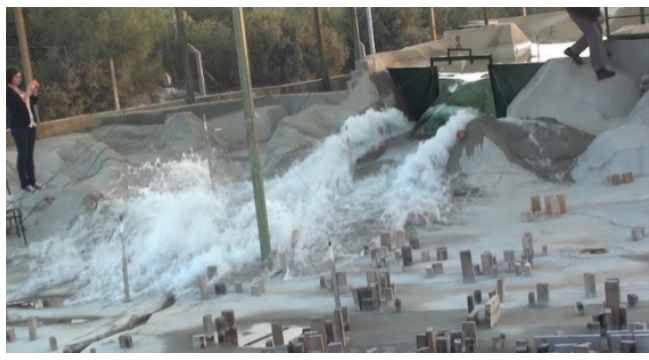

Şekil 19. Ani yıkılma durumunda taşkın dalgasının 2 s sonra ulaștığı noktalar

Taşkın dalgasının 4 s sonra ulaştığı noktalar trapez gedik, üçgen gedik ve ani yıkılma durumlarında sırasıyla Şekil 20, 21 ve 22 'de verilmektedir.

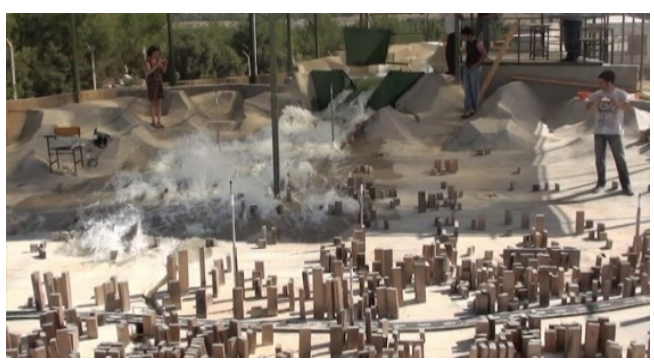

Şekil 20. Trapez gedik durumunda taşkın dalgasının 4 s sonra ulaștığı noktalar

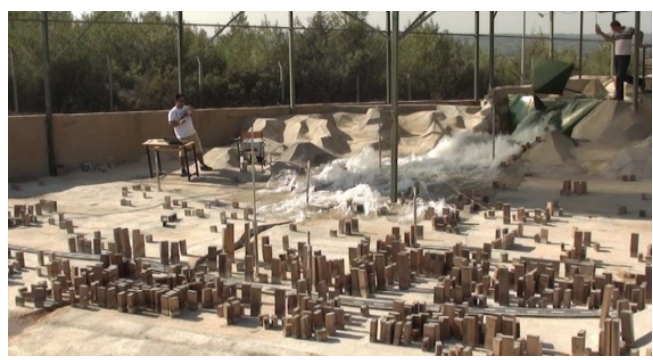

Şekil 21. Üçgen gedik durumunda taşkın dalgasının 4 s sonra ulaștı̆̆ı noktalar

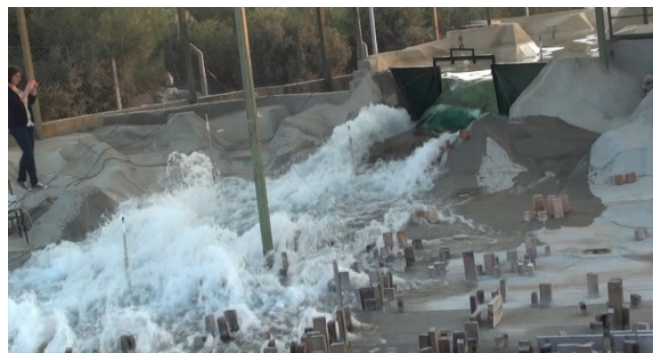

Şekil 22. Ani yıkılma durumunda taşkın dalgasının 4 s sonra ulaștığı noktalar

Taşkın dalgasının 8 s sonra ulaştı̆̆ı noktalar trapez gedik, üçgen gedik ve ani yıkılma durumlarında sırasıyla Şekil 23, 24 ve $25^{\prime}$ te verilmektedir.

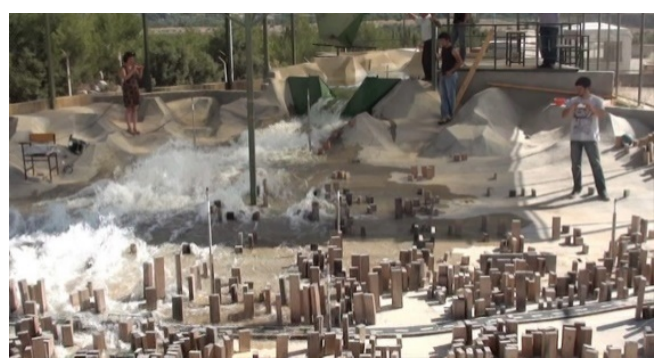

Şekil 23. Trapez gedik durumunda taşkın dalgasının 8 s sonra ulaștığı noktalar

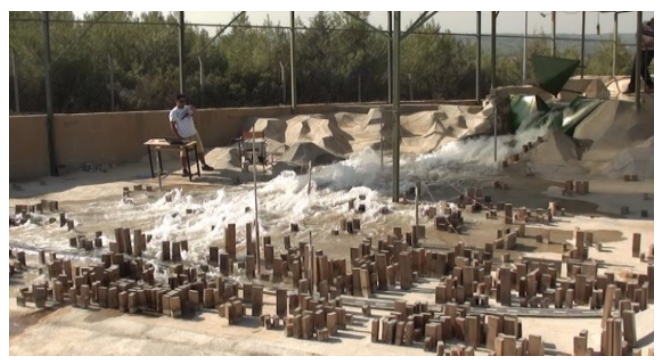

Şekil 24. Üçgen gedik durumunda tașkın dalgasının 8 s sonra ulaştığı noktalar 
DEÜ FMD 22(66), 887-896, 2020

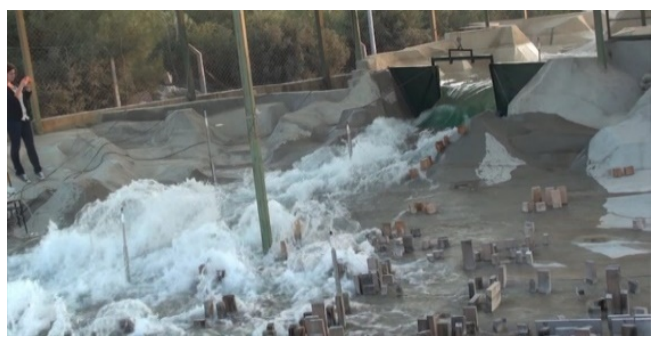

Şekil 25. Ani yıkılma durumunda taşkın dalgasının 8 s sonra ulaștığı noktalar

Farklı yıkılma senaryoları sonrasında elde edilen maksimum derinlikler Tablo 2'de, farklı yıkılma senaryoları sonrasinda $\mathrm{U} 1$ ve U4 algılayıcılarından elde edilen maksimum hızlar örnek olarak Tablo 3'te, farklı yıkılma senaryoları sonrasında taşkın dalgasının S2 seviye ölçerine, S6 seviye ölçerine, karayoluna ve denize ulașması için geçen süreler Tablo 4'te verilmektedir.

Tablo 2. Farklı ölçüm noktalarında ölçülen maksimum derinlikler

\begin{tabular}{cccc}
\hline $\begin{array}{c}\text { Seviye } \\
\text { Ölçer }\end{array}$ & $\begin{array}{c}\text { Trapez } \\
\text { Gedik }\end{array}$ & $\begin{array}{c}\text { Üçgen } \\
\text { Gedik }\end{array}$ & $\begin{array}{c}\text { Ani } \\
\text { Ylkılma }\end{array}$ \\
\hline S1 (cm) & 100,0 & 100,0 & 95,3 \\
S2 (cm) & 9,4 & 7,0 & 10,3 \\
S3 (cm) & 10,6 & 10,4 & 9,0 \\
S4 (cm) & 5,7 & 4,7 & 8,3 \\
S5 (cm) & 4,1 & 3,4 & 4,5 \\
S6 (cm) & 4,7 & 4,7 & 4,6 \\
S7 (cm) & 6,3 & 5,9 & 6,5 \\
S10 (cm) & 5,3 & 4,4 & 6,4 \\
S11 (cm) & 7,1 & 6,8 & 8,1 \\
\hline
\end{tabular}

Tablo 3. Farklı ölçüm noktalarında ölçülen maksimum hizlar

\begin{tabular}{cccc}
\hline $\begin{array}{c}\text { Seviye } \\
\text { Ölçer }\end{array}$ & $\begin{array}{c}\text { Trapez } \\
\text { Gedik }\end{array}$ & $\begin{array}{c}\text { Üçgen } \\
\text { Gedik }\end{array}$ & $\begin{array}{c}\text { Ani } \\
\text { Yıkılma }\end{array}$ \\
\hline $\mathrm{U} 1(\mathrm{~m} / \mathrm{s})$ & 5,64 & 6,84 & 5,64 \\
$\mathrm{U} 4(\mathrm{~m} / \mathrm{s})$ & 1,92 & 3,17 & 4,69 \\
\hline
\end{tabular}

Bu çalışma TÜBİTAK 110M240 nolu proje kapsamında maddi olarak desteklenmiş olup TÜBİTAK'a ve gerekli verileri temin ettiğimiz DSİ İzmir Bölge Müdürlüğü ve İZSU Genel Müdürlüğüne müteşekkiriz. ulașım süresi

\begin{tabular}{cccc}
\hline $\begin{array}{c}\text { Ulaşılan } \\
\text { Yer }\end{array}$ & $\begin{array}{c}\text { Trapez } \\
\text { Gedik }\end{array}$ & $\begin{array}{c}\text { Üçgen } \\
\text { Gedik }\end{array}$ & $\begin{array}{c}\text { Ani } \\
\text { Ylkılma }\end{array}$ \\
S2 (s) & 2 & 2 & 2 \\
S6 (s) & 4 & 4 & 3 \\
Karayolu (s) & 6 & 6 & 5 \\
Deniz (s) & 8 & 8 & 6 \\
\hline
\end{tabular}

\section{Sonuçlar}

Baraja yakın bölgelerde su derinliği $10 \mathrm{~cm}$ mertebesinde ölçülmüș olup prototipte $3 \mathrm{~m}$ ' lik bir derinliğe karşıllk gelmektedir. $\mathrm{Bu}$ da $\mathrm{o}$ bölgede bulunan evlerin 1 . katının su ile dolacağı anlamına gelmektedir. Evlerin yoğun olduğu bölgede $8 \mathrm{~cm}$ mertebesinde derinlikler ölçülmüş olup doğada 2,40 m'lik derinlik değerine karşıllk gelmektedir.

Baraj çıkışında modelde ölçülen $6,00 \mathrm{~m} / \mathrm{s}$ mertebesindeki hız değerleri doğada 32,88 $\mathrm{m} / \mathrm{s}^{\prime}$ lik bir hıza karşı gelmekte olup önemli hasarlar yaratabilecek mertebededir. Yoğun yerleşimin olduğu bölgelerde ölçülen 1-4,5 $\mathrm{m} / \mathrm{s}^{\prime}$ lik hızlar ise doğada $5,48 \mathrm{~m} / \mathrm{s}$ ve 24,66 $\mathrm{m} / \mathrm{s}^{\prime}$ lik değerlere karşıllk gelmektedir. $\mathrm{Bu}$ mertebede hızların yaratacağı hidrodinamik etki önemli can ve mal kayılarına sebep olabilecektir.

Taşkın dalgası 2 s içinde baraja yakın bölgeyi tamamen etkilemekte olup doğada yaklașlk 55 s'lik bir süreye denk gelmektedir. Ani yıkılmada modelde 6 s sonrasında taşkın dalgasının denize ulaștığı gözlemlenmiștir. Bu değer doğada 164,4 s'lik bir süreye karşılık gelmektedir. Taşkın dalgasının modelde 13 s sonrasında, doğada ise 356,2 s sonrasında oldukça sönümlendiği gözlemlenmiștir. Modelde $21 \mathrm{~s}$ (prototipte yaklaşık $10 \mathrm{dk}$ ) sonra göl suyunun çok önemli bir kısmının boşaldığı ve taşkın dalgasının da çok daha fazla sönümlendiği, $30 \mathrm{~s}$ sonra ise (prototipte yaklaşık $14 \mathrm{dk}$ sonrasında) taşkın dalgasının tamamen şiddetini yitirdiği tespit edilmiştir.

\section{Teşekkür}




\section{Kaynakça}

[1] Leal, J. G. A. B., Ferreira, R. M. L., Franco, A. B. ve Cardoso, A. H. 2002. Dam-break waves on movable beds. In Bousmar\&Zech (eds) Riverflow2002, Volume 2, 981-990.

[2] Bellos, C. V. 2004. Experimental measurements of flood wave created by a dam break. EWRA, European Water, 7/8: 3-15.

[3] Testa, G., Zuccala, D., Alcrudo, F., Mulet, J. ve SoaresFrazao, S. 2007. Flash flood flow experiment in a simplified urban district. Journal of Hydraulic Research, 45, 37-44.

[4] Alcrudo, F. ve Mulet, J. 2007. Description of the Tous dam break case study. Journal of Hydraulic Research 45, 45-57.

[5] http://maps.google.com (Erişim tarihi 02.03.2020)

[6] Yalın, M. S., 1971. Theory of Hydraulic Models. The Macmillan Press Ltd, London.

[7] http://www.met-flow.com (Erişim tarihi 02.03.2020)

[8] M. Ş. Güney, G. Tayfur, T. Arkıș, G. Bombar 2015, Experimental and numerical investigation of flood propagation due to trapezoidal breach in the distorted physical model of Ürkmez dam, Dam Engineering, Vol XXV, issue 4, pp. 171- 187.

[9] M. S. Güney, G. Tayfur and T. Arkıs 2015 Experimental investigation of the hydrograph characteristics effect on the flood propagation due to the failure of the distorted physical model of Ürkmez dam. ACSEE 2015 / Proc. of The Third Intl. Conf. On Advances in Civil, Structural and Environmental Engineering, Zurich, Switzerland. 